\title{
Pemanfaatan Media Komik Digital Melalui Unsur PPR (Paradigma Pedagogi Reflektif) Pada Matakuliah Sejarah Asia Barat Modern
}

\author{
Brigida Intan Printina \\ Universitas Sanata Dharma \\ Email: intanbrigida@usd.ac.id / brigidaintan91@gmail.com
}

\begin{abstract}
The Use of Digital Comic Media in Modern West Asian History Courses has been developed as an effective medium in learning. For this reason, this study aims to analyze about 1) Digital Comic Media Through the Elements of PPR (Reflective Pedagogy Paradigm); 2) Results of action from Digital Comic Media. The method used is qualitative research that describes activities or information about ongoing class conditions. The research data was collected through observation with a sampling technique known as purposive sampling. The sample used is one of the informants to get information about the right media. The results showed that 1) the use of digital comic media in Modern West Asian History courses was carried out through 3 elements, namely Competence including mastery of one of the material in the subject of Modern West Asian History, Concern described through reflection in digital comics, and Compassion extracting action through the use of digital comics that are in accordance with the relevance of learning regional history for the progress of the nation; 2) of the 50 students who take the Modern West Asian History course there are $60 \%$ of students who get $A$ grade, get B score as much as $28 \%$ of students, and get $C$ score of $6 \%$ of students, and the rest do not take lectures from the beginning.
\end{abstract}

Keywords : Media, Digital Comics, Reflective Pedagogical Paradigm, Modern Western Asian History

\begin{abstract}
Pemanfaatan Media Komik Digital Pada Matakuliah Sejarah Asia Barat Modern telah dikembangkan sebagai media yang efektif dalam pembelajaran. Untuk itu, penelitian ini bertujuan menganalisis tentang 1) Media Komik Digital Melalui Unsur PPR (Paradigma Pedagogi Reflektif) ; 2) Hasil aksi dari Media Komik Digital. Metode yang digunakan adalah penelitian kualitatif yang menggambarkan tentang kegiatan atau informasi tentang kondisi kelas yang sedang berlangsung. Data penelitian dikumpulkan melalui observasi dengan teknik cuplikan yang dikenal dengan purposive sampling. Sampel yang digunakan adalah salah satu informan untuk mendapatkan informasi mengenai media yang tepat. Hasil penelitian menunjukan bahwa 1) pemanfaatan media komik digital pada mata kuliah Sejarah Asia Barat Modern telah dilakukan melalui 3 unsur yaitu Competence meliputi penguasaan salah satu materi pada mata kuliah Sejarah Asia Barat Modern, Concience yang diuraikan melalui refleksi di komik digital,dan Compassion penggalian aksi melalui pemanfaatan komik digital yang sesuai dengan relevansi pembelajaran sejarah kawasan bagi kemajuan bangsa; 2) dari 50 mahasiswa yang mengikuti mata kuliah Sejarah Asia Barat Modern ada $60 \%$ mahasiswa yang mendapat nilai A, mendapat nilai B sebanyak $28 \%$ mahasiswa, dan mendapatkan nilai $\mathrm{C}$ sebanyak $6 \%$ mahasiswa, dan sisanya tidak mengikuti perkuliahan sejak awal.
\end{abstract}

Kata kunci : Media, Komik Digital, Sejarah Asia Barat Modern 


\section{PENDAHULUAN}

Posisi dunia pendidikan berada pada era yang mengancam tatanan dan nilai karakter yang ada pada bangsa. Ancaman tersebut muncul seiring berkembangnya teknologi informasi yang semakin hari semakin terjangkau dan mampu menyediakan kebutuhan manusia. Hal ini menandakan masyarakat kita ada pada tatanan baru yang dinamakan Revolusi Industri 4.0. Selaku pendidik ada berbagai hal yang dapat mengubah ancaman tersebut menjadi peluang, salah satunya pemanfaatan media pembelajaran sejarah. Pembelajaran sejarah tanpa media di era ini pun terasa dangkal oleh generasi digital.

Proses pembelajaran yang sesungguhnya mengandung lima komponen komunikasi yaitu, guru (komunikator), bahan pembelajaran dan media pembelajaran. Jadi, media pembelajaran merupakan segala sesuatu yang dapat digunakan untuk menyalurkan pesan (bahan pembelajaran), sehingga dapat merangsang perhatian, minat, pikiran, dan perasaaan sisswa dalam kegiatan belajar untuk mencapai tujuan belajar (I Wayan Santyasa, 2007; 3). Robinson, Molenda, dan Rezabek (2008: 40-41) mengungkapkan "Some enthusiasts for using media improve learning seem to assume that merely ambedding the content into a newer media format will automatically improve its effectiveness". Pemanfaatan media pembelajaran dapat menimbulkan antusiasme pembelajar yang secara otomatis meningkatkan efektifitas pembelajar. Dalam hal ini media komik digital menjadi salah satu sarana yang tepat untuk membangkitkan kesadaran sejarah sekaligus mengembalikan karakter bangsa yang sesungguhnya.

Berbagai kajian mengenai komik digital dalam pembelajaran sejarah menjadi acuan penelitian ini. Penelitian Ijang Permana Sidik yang berjudul Efektifitas Media Komik Digital Terhadap Peningkatan Hasil Belajar Siswa 
Pada Mata Pelajaran Sejarah menunjukkan bahwa media komik digital efektif dalam meningkatkan hasil blajar siswa dalam ranah kognitif.

Kajian Marcel Bonnef (1998:8) mengenai Komik Indonesia juga menjadi salah satu referensi dalam penelitian ini. Menurut pandangannya komik mengandung aspek grafis dimaa para pembaca sulit membayangkan realitas dari buku bacaan biasa sehingga gambar komik dibuat sederhana agar setiap orang mampu mencernanya. Komik juga mampu menyumbang beberapa unsur yang berguna untuk menjawab masalah yang lebih umum saat ini, yaitu gambaran yang khas Indonesia.

Pembelajaran berpola PPR adalah pembelajaran yang mengintegrasikan pembelajaran bidang studi dengan pengembangan nilai-nilai kemanusiaan. Pembelajaran bidang studi disesuaikan dengan konteks siswa, sedangkan pengembangan nilai-nilai kemanusiaan ditumbuh-kembangkan melalui dinamika pengalaman, refleksi, dan aksi. Pembelajaran ini dikawal dengan evaluasi (Subagya, 2010:51).

Tujuan dari pembelajaran PPR terwujud dalam 3 unsur yang ada pada tujuan pembelajaran. Ketiga unsur tersebut adalah Competence, Conscience, dan Compassion. Competence merupakan kemampuan secara kognitif atau intelektual, Conscience ialah kemampuan afektif dalam menentukkan pilihan-pilihan yang dapat dipertanggungjawabkan secara moral, sedangkan Compassion adalah kemampuan dalam psikomotorik yang berupa tindakan konkret maupun batin disertai sikap bela rasa bagi sesame (Subagya, 2010: 23-24)

Penerapan PPR dalam pembelajaran melalui sebuah siklus yang terdiri atas 5 unsur-unsur pokok. Unsur-unsur pokok tersebut yaitu: konteks (context), pengalaman (experience), refleksi (reflection), tindakan (action), dan evaluasi (evaluation) (P3MP, 2008:8). Unsur yang digunakan dalam 
artikel ini hanya meliputi 2 unsur yaitu refleksi dan tindakan, karena pemanfaatan komik digital untuk memenuhi salah satu tugas dalam perkuliahan Sejarah Asia Barat Modern.

Dari urian diatas, maka dapatlah digambarkan tujuan penulisan artikel ini diantaranya untuk memaparkan pelaksanaan hingga hasil media komik digital pada matakuliah Sejarah Asia Barat Modern. Para mahasiswa menunjukkan antusiasme dan menjiwai semangat nasionalisme hal ini tampak pada analisis data yang telah dilakukan.

\section{METODE}

Penelitian ini dilaksanakan pada mata kuliah Sejarah Asia Modern Tahun ajaran 2018/2019. Penelitian ini merupakan penelitian kualitatif deskriptif. Sumber data diperoleh dari mahasiswa angkatan 2017 (Semester III), Program Studi Pendidikan Sejarah FKIP Universitas Sanata Dharma Yogyakarta. Dokumen yang diteliti merupakan media pembelajaran yang melalui penugasan berupa komik digital dan daftar nilai.

Teknik Pengumpulan data salah satunya Observasi yaitu menggali data dari sumber data yang berupa peristiwa, aktivitas, perilkau, tempat atau lokasi, dan benda serta rekaman gambar. (HB. Sutopo, 2006: 67-69) Penelitian ini menggunakan teknik cuplikan yang dikenal dengan purposive sampling (sample bertujuan). (Sutopo, 2006: 64). Peneliti memilih salah satu informan dianggap dapat menjawab informasi yang berkaitan dengan pemanfaatan media pembelajaran komik digital. Validitas data dalam penelitian ini menggunakan trianggulasi sumber/data dan metode.

Tenik analisis data secara khusus kegiatannya dilakukan secara induktif, interaktif dari setiap unit datanya bersamaan dengan proses pelaksanaan pengumpulan data. 


\section{HASIL}

Data yang diperoleh dari penelitian ini diantaranya komik digital hasil karya mahasiswa terkait materi yang ada pada silabus yang didalamnya memuat materi Analisa Konflik Timur Tengah (Asia Barat) Abad Modern,Nasionalisme Turki Pasca Imperium, Nasionalisme di NegaraNegara Arab, Perjuangan dan Pergolakan di Yaman, Lahirnya Nasionalisme Mesir dan Kepentingan Barat, Kemerdekaan Suriah dan Libanon Tahun 1941, Perang Arab Israel, Perang Israel-Palestina, Perjuangan Kemerdekaan Iran Pendudukan dan Nasionalisme Irak, Perang Teluk I, Perang Teluk II, dan Perang Teluk III.

Setiap komik berisi dialog mengenai materi dan refleksi akar permasalahan yang juga dapat menjadi solusi atas permasalahan bangsa Indonesia, karena kedua bangsa memiliki cirikhas yang sama untuk beberapa bidang. Berikut merupakan hasil komik yang diambil secara acak dari beberapa karya mahasiswa angkatan 2017 (Semester III)pada mata kuliah Sejarah Asia Modern Tahun ajaran 2018/2019.Program Studi Pendidikan Sejarah FKIP Universitas Sanata Dharma Yogyakarta. 


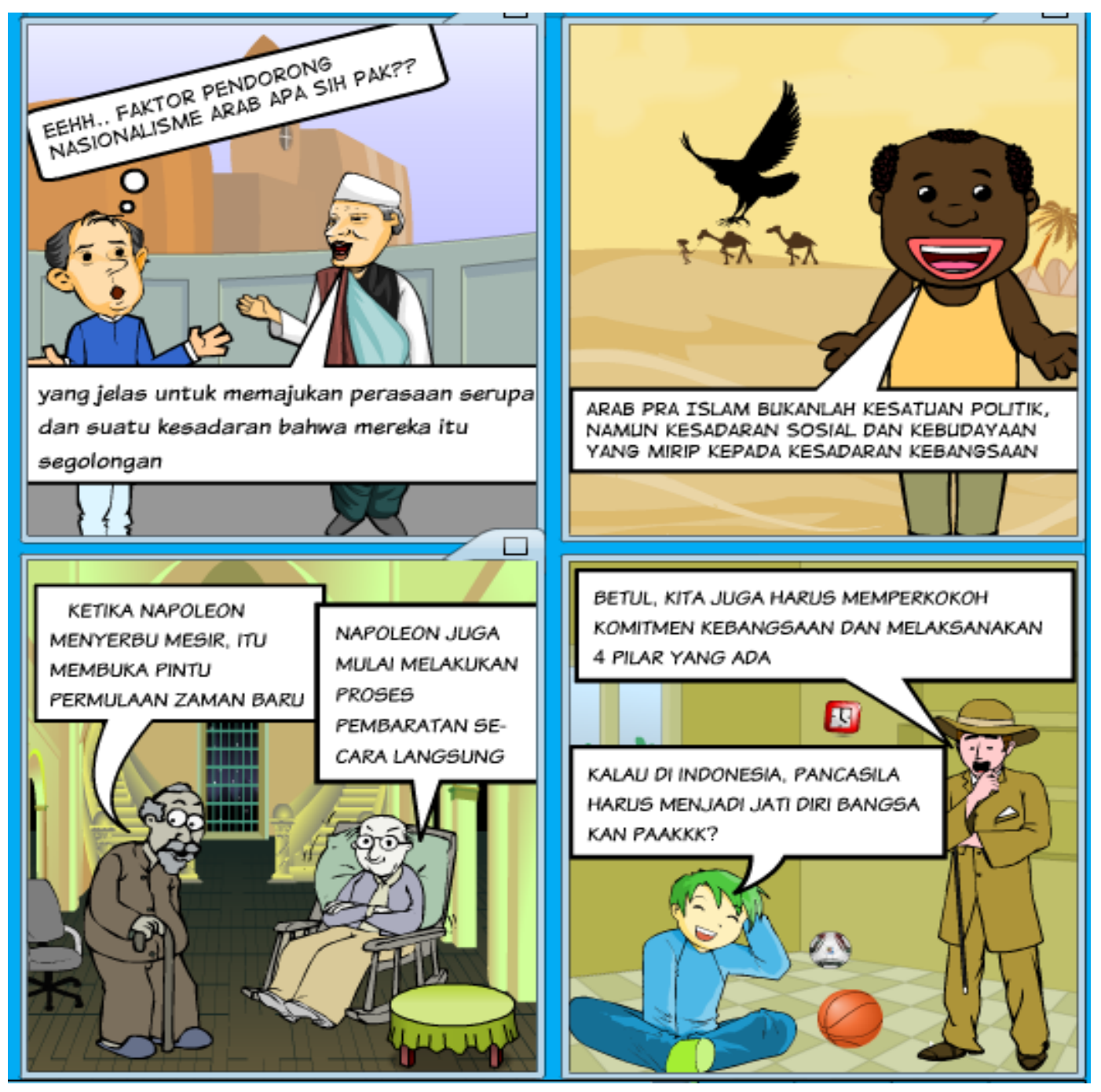

Gambar 1.

Nasionalisme dan Para Pelopor Bersatu untuk Bangsa Arab, karya Yoas Tri Joko Purnomo

Gambar 1 mendeskripsikan karya Yoas Tri Joko Purnomo mengenai Nasionalisme dan Para Pelopor Bersatu untuk Bangsa Arab. Ketika Napoleon Bonaparte menyebarkan pengaruh Revolusi Perancis (liberte, egalite, dan fraternite) banyak pelopor nasionalisme Arab yang memiliki misi menyelamatkan bangsanya terbebas dari tradisi yang terlalu konservatif untuk tetap memajukan bangsa serta terbebas dari penetrasi asing diantaranya Sultan Abdul Hamid II(Turki),Al-Tahtawi (Mesir), Muhammad Rashid Rida (Syria), Mustafa Kemal Ataturkh (Turki), Gammal Abdul Nasser (Mesir). Maka, hal ini merupakan gagasan yang sama dengan apa 
yang dikemukakan Soekarno sebagai nasionalis bangsa bahwa setiap warga mampu mempertahankan ideology bangsa dari segala ancaman yang ada.
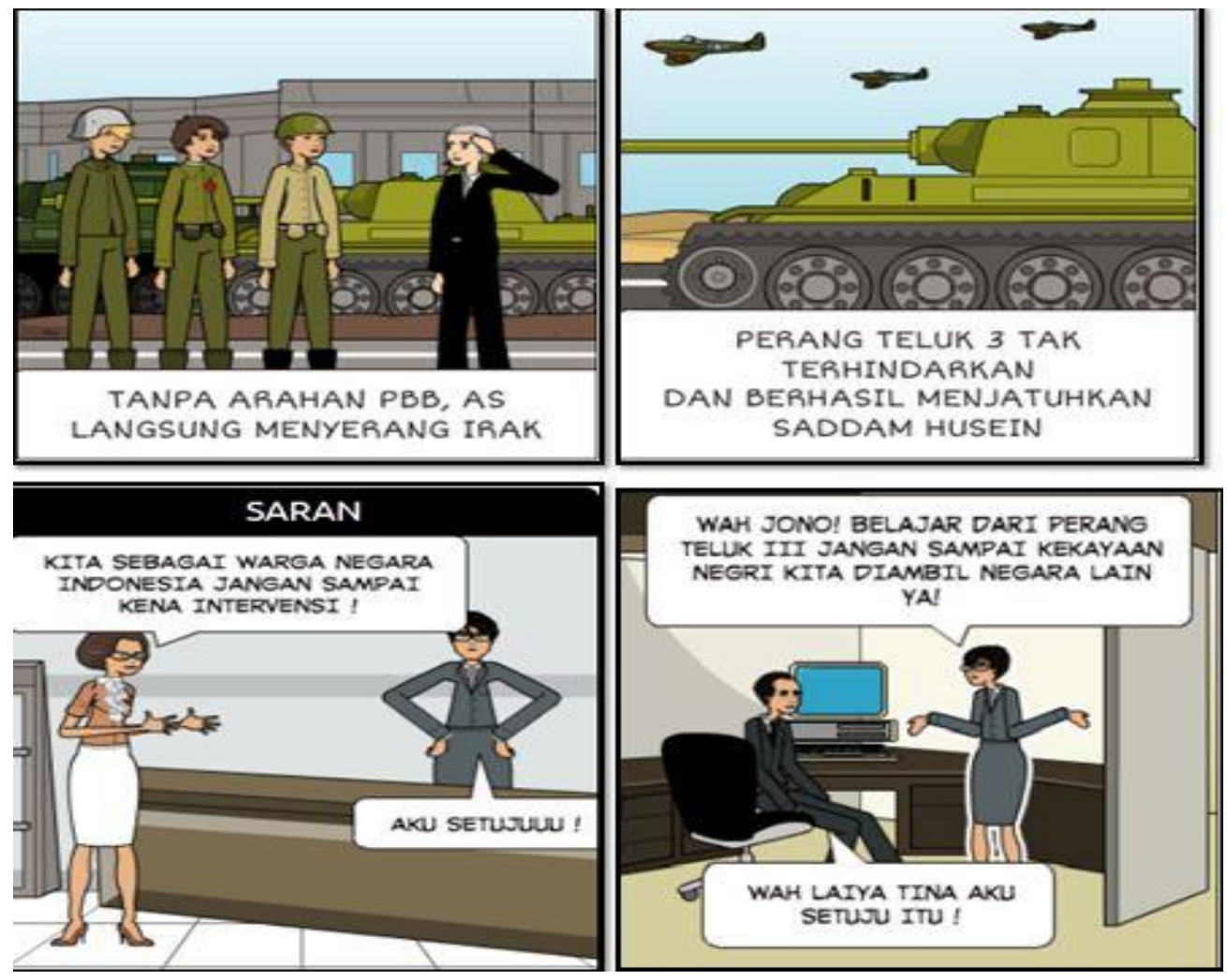

Gambar 2. Perang Teluk III Karya Agung Karuniasthi

Gambar 2 menguraikan karya komi digital dari Agung Karuniasthi mengenai Perang Teluk III bahwa Amerika Serikat lebih menanamkan pengaruh ideologinya melalui jalinan mitra dengan beberapa wilayah yang terkena konflik diantaranya Iran, Kuwait, Israel, dan membendung kekuatan radikal seperti Saddam Husein dalam Perang Teluk III. Maka, di era ini setiap generasi mampu bercermin dari segala situasi di waktu dan belahan dunia manapun untuk dapat menata bangsa Indonesia agar tidak tertimpa masalah serupa. 

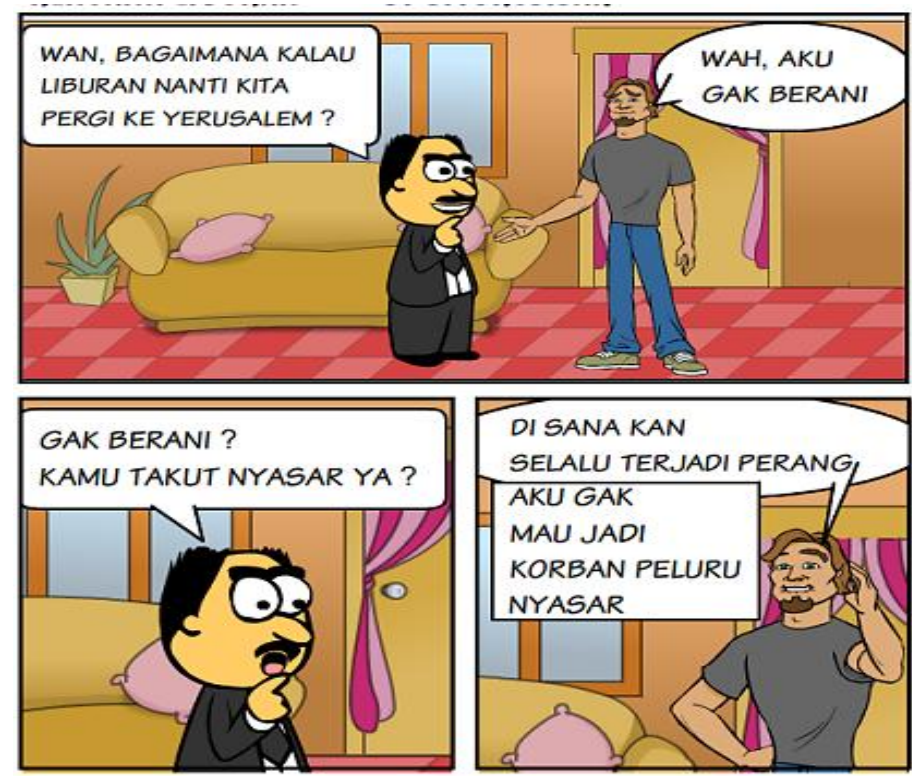

Gambar 3.

Belajar Untuk Mencintai Indonesia dari Konflik Arab dan Israel karya Agustinus Isak Sitorus (Vol 1)
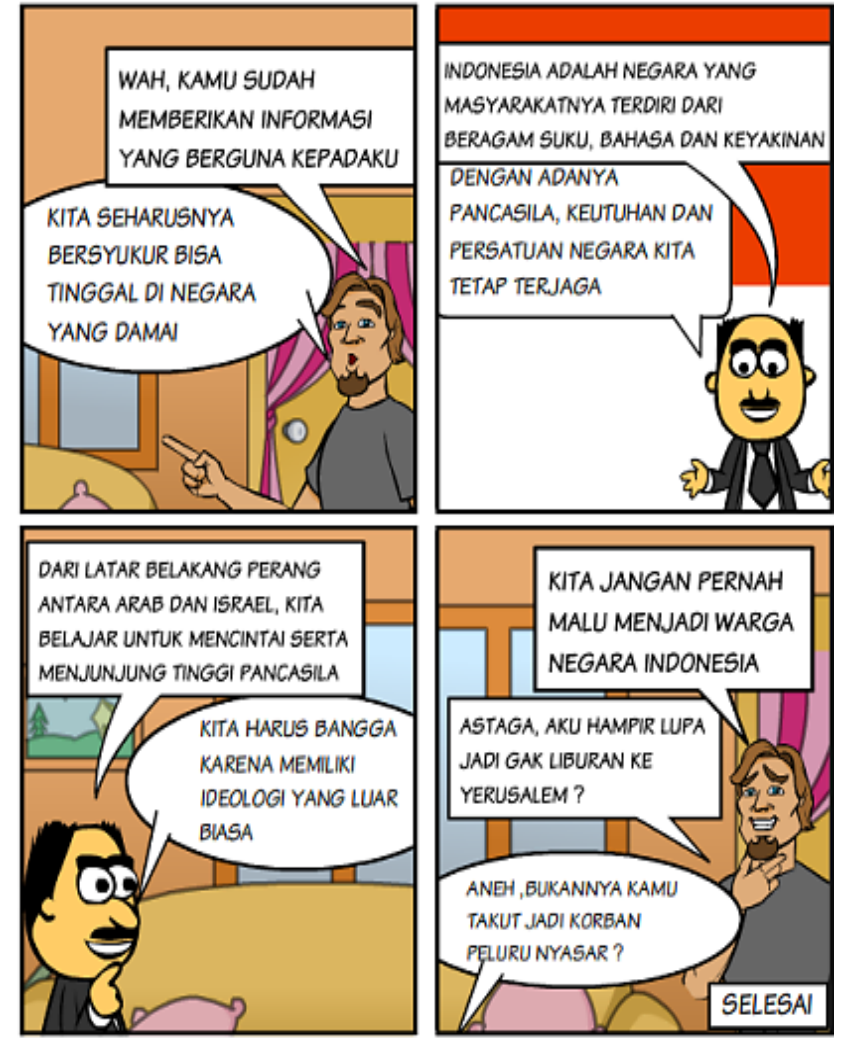

Gambar 4.

Belajar Untuk Mencintai Indonesia dari Konflik Arab dan Israel karya Agustinus Isak Sitorus (Vol 1) 
Gambar 3 dan Gambar 4 dijabarkan secara jelas oleh Agustinus Isak Sitorus bahwa kemajuan bangsa terletak pada situasi dan kondisinya. Apabila negara itu dapat menjaga perdamaian maka warga dunia juga ikut berpartisipasi membangun negara kita, karena tidak hanya SDA yang kita miliki namun juga karakter budaya yang amat diminati warga dunia layaknya Yerusalem sebagai salah satu negara pelopor perdamaian dunia.

Demikian beberapa komik digital hasil karya mahasiswa, semuanya ditekankan untuk membawa misi yang baik untuk masa depan bangsa lewat refleksi yang ada.

\section{PEMBAHASAN}

Hasil karya mahasiswa terkait materi Sejarah Asia Barat Modern yang ada pada silabus dan dibuat dalam bentuk komik digital telah menunjukkan hasil yang sesuai berdasarkan evaluasi yang telah dilakukan.

Diagram 1. Hasil Aksi Penugasan Komik Digital pada mata kuliah Sejarah Asia Barat Modern

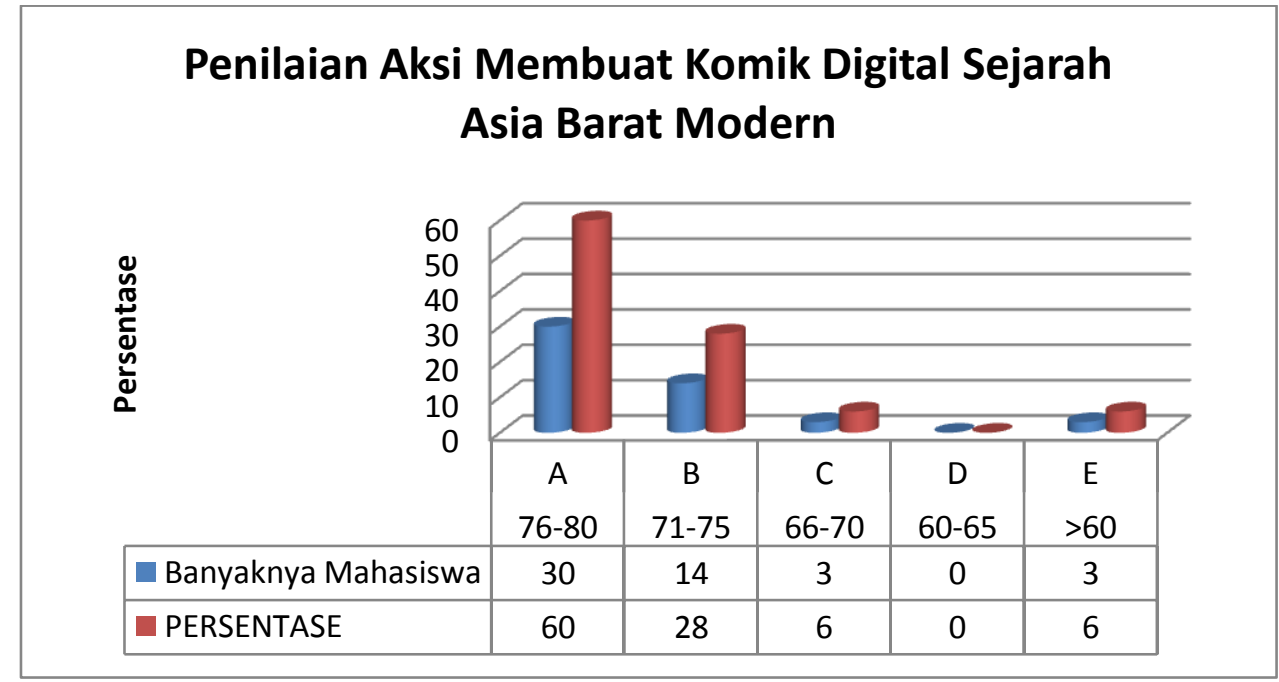

Hasil pada diagram tersebut menunjukkan bahwa dari 50 mahasiswa yang mengikuti mata kuliah Sejarah Asia Barat Modern ada 60\% mahasiswa yang mendapat nilai A, mendapat nilai B sebanyak 28\% mahasiswa, dan 
mendapatkan nilai C sebanyak 6\% mahasiswa, dan sisanya tidak mengikuti perkuliahan sejak awal.

Hasil penelitian berupa komik digital pada mata kuliah Sejarah Asia Barat Modern juga menujukkan bahwa segala persitiwa yang ada diantaranya perjuangan nasionalisme bangsa-bangsa Arab, perjuangan melawan penetrasi asing, hingga meningkatkan toleransi di negara berkacamata dari Yerusalem merupakan sesuatu pencapaian yang maksimal dari pemanfaatan media pembelajaran sejarah. Hal ini sejalan dengan apa yang dikaji oleh Robinson, Molenda, dan Rezabek (2008: 40-41) yang mengungkapkan "Some enthusiasts for using media improve learning seem to assume that merely ambedding the content into a newer media format will automatically improve its effectiveness". Pemanfaatan media pembelajaran dapat menimbulkan antusiasme pembelajar yang secara otomatis meningkatkan efektifitas pembelajar.

Seperti yang telah dilakukan oleh mahasiswa angkatan 2017 (Semester III), Program Studi Pendidikan Sejarah FKIP Universitas Sanata Dharma Yogyakarta, pada mata kuliah Sejarah Asia Modern yang menggunakan media komik digital sebagai sarana menuangkan gagasan untuk memajukan bangsa dan menumbuhkan semangat nasionalisme. Hal tersebut selaras dengan gagasan Kajian Marcel Bonnef (1998:8) yang menegaskan bahwa Komik Indonesia dapat menjadi salah satu referensi dalam penelitian ini. Komik juga mampu menyumbang beberapa unsur yang berguna untuk menjawab masalah yang lebih umum saat ini, yaitu gambaran yang khas Indonesia.

Salah satu pemaknaan sebagai pendidikan karakter yang dapat diambil dalam menjawab tantangan Revolusi Industri 4.0 ialah penggunaan pendekatan pembelajaran yang dapat mengimbangi media pembelajaran 
sejarah dengan menggunakan komik digital yaitu Paradigma Pedagogi Reflektif (PPR). Hal ini sejalan dengan kajian Subagya, (2010: 23-24) bahwa Competence merupakan kemampuan secara kognitif atau intelektual, Conscience ialah kemampuan afektif dalam menentukkan pilihan-pilihan yang dapat dipertanggungjawabkan secara moral, sedangkan Compassion adalah kemampuan dalam psikomotorik yang berupa tindakan konkret maupun batin disertai sikap bela rasa bagi sesame (Subagya, 2010: 23-24). Competence merupakan bagian dari penguasaan salah satu materi pada mata kuliah Sejarah Asia Barat Modern. Unsur Refleksi merupakan salah satu aspek Conscience dan aksi ialah Compassion.

Keterbatasan dalam penelitian ini adalah tidak semua unsur PPR diuraikan karena fokus pada beberapa unsure saja yaitu aksi dan refleksi. Namun, hal ini menjadi fokus kajian karena seringkali dalam perkuliahan kedua hal ini sulit untuk diimplementasikan.

Adapun implikasi terhadap bidang keilmuan bahwa Pemanfaatan media komik digital dapat digunakan di semua jenjang pendidikan, sedangkan untuk pembuatannya khusus untuk siswa setingkat sekolah menengah hingga perguruan tinggi. Setiap pendidik juga dapat berkolaborasi untuk mengasilkan media pembelajaran sejarah yang tepat guna demi penanaman karakter dan masa depan bangsa.

\section{KESIMPULAN}

Hasil penelitian Media Komik Digital Melalui Unsur PPR (Paradigma Pedagogi Reflektif) pada Matakuliah Sejarah Asia Barat Modern mendeskripsikan Materi Sejarah Asia Barat Modern. Ada 3 prinsip PPR yang digunakan yaitu Competence merupakan bagian dari penguasaan salah satu materi pada mata kuliah Sejarah Asia Barat Modern. Unsur Refleksi 
merupakan salah satu aspek Conscience dan aksi ialah Compassion. Setiap komik berisi dialog mengenai materi dan refleksi akar permasalahan yang juga dapat menjadi solusi atas permasalahan bangsa Indonesia, karena kedua bangsa memiliki cirikhas yang sama untuk beberapa bidang.

Dari 50 mahasiswa yang mengikuti mata kuliah Sejarah Asia Barat Modern ada $60 \%$ mahasiswa yang mendapat nilai $\mathrm{A}$, mendapat nilai $\mathrm{B}$ sebanyak 28\% mahasiswa, dan mendapatkan nilai C sebanyak 6\% mahasiswa, dan sisanya tidak mengikuti perkuliahan sejak awal. Hasil penelitian berupa komik digital pada mata kuliah Sejarah Asia Barat Modern juga menujukkan bahwa segala persitiwa yang ada diantaranya perjuangan nasionalisme bangsa-bangsa Arab, perjuangan melawan penetrasi asing, hingga meningkatkan toleransi di negara berkacamata dari Yerusalem merupakan sesuatu pencapaian yang maksimal dari pemanfaatan media pembelajaran sejarah.

Dalam bidang keilmuan, Pemanfaatan media komik digital dapat digunakan di semua jenjang pendidikan, sedangkan untuk pembuatannya khusus untuk siswa setingkat sekolah menengah hingga perguruan tinggi. Setiap pendidik juga dapat berkolaborasi untuk mengasilkan media pembelajaran sejarah yang tepat guna demi penanaman karakter dan masa depan bangsa.

\section{DAFTAR PUSTAKA}

[1]. Bonnef, Marcel. (1998). Komik Indonesia. Jakarta: KPG

[2]. P3MP-USD. 2008. Model Pembalajaran Berbasis Pedagogi Ignasian. Yogyakarta: Universitas Sanata Dharma

[3]. Subagyo. 2010. Paradigma Pedagogi Reflektif Mendampingi Peserta Didik Menjadi Cerdas dan Berkarakter. Yogyakarta: Kanisisus 
[4]. Sutopo. H.B. (2006). Metodologi Penelitian Kualitatif: Dasar Tori dan Terapannya dalam Penelitian Pendidikan Edisi Kedua. Surakarta: UNS Press.

[5]. Santayasa, I Wayan. (2007). Makalah Workshop Media Pembelajaran bagi Guru-Guru SMA Negeri Banjar Angkan pada tanggal 10 Januari 2007. Banjar: Angkan Klungkung.

[6]. www.toondoo.com link pembuatan komik digital 